Diabetologia 10,617-623 (1974)

(c) by Springer-Verlag 1974

\title{
Further Characterization of Diabetes-Like Abnormalities in the T-KK Mouse
}

\author{
B.M. Wyse and W.E. Dulin \\ Diabetes and Atherosclerosis Research, The Upjohn Company, Kalamazoo, MI, USA
}

\begin{abstract}
Summary. The sequence of development and regression of several abnormalities of T-KK mice was studied in comparison with $\mathrm{C} 57 \mathrm{BL} / 6$ mice. Food intake, body weights, blood sugars and plasma insulins were determined at approximately monthly intervals from $2-16$ months. Insulin sensitivity, glucose tolerance and in vivo gluconeogenesis were studied at about 2 months, $5-6$ months and at one year. Plasma growth hormone and glucose oxidation by isolated islets were also studied and determination of life span was made. - It was not possible to determine which abnormality occurred first in the T-KK mouse, since at 2 months significant changes in all parameters were already present. The reversal of plasma insulin and blood glucose occurred before the decreased food intake and body woights. These results were interpreted to mean that the changes in insulin and glucose may be under genetic control. - Insulin sensitivity and tolerance to glucose decreased and in vivo gluconeogenesis increased when the T-KK mice were obese, hyperglycemic and
\end{abstract}

hyperinsulinemic. These changes reverted to normal after the animals lost weight and blood sugars and plasma insulin had returned to normal. Survival dropped in T-KK mice and these earlier deaths appeared to coincide with normalization of body weight, blood sugar and plasma insulin. These observations indicated that the abnormalities in the T-KK mouse are of importance to survival. - Plasma growth hormone was decreased in the fasted T-KK mice and there was no difference from normal when animals were fed. Therefore, an increase in growth hormone does not play a role in the pathogenesis of abnormalities in the T-KK mouse. Oxidation of glucose${ }^{1-14} \mathrm{C}$ and $-6{ }^{14} \mathrm{C}$ in isolated islets from $\mathrm{T}-\mathrm{KK}$ mice was increased therefore confirming the hyperactivity of the islets.

Key words: Diabetes, T-KK mice, hyperglycemia, normalization, hyperinsulinemia, growth hormone, islets.
The KK mouse and a related strain arising from the KK X C57BL/6J cross (T-KK) have been shown to exhibit hyperinsulinism, elevated pancreatic insulin, glucose intolerance, hyperphagia, obesity, and insulin resistance $[1-13]$. The variability of these changes has been shown to be extensive in inbred lines $[5,10,13]$ and most of the abnormalities revert to normal with age $[5,13]$. The genetic background of this syndrome is complex and it has not been possible to establish inbred lines which produce $100 \%$ diabetes; this may explain some of the variability $[6,13]$. The purpose of the studies reported in this paper was to gain a better understanding of the causative factor(s) in the development and regression of abnormalities of the T-KK mouse.

\section{Materials and Methods}

\section{Animals}

All animals were males. The C57BL/6 mice were obtained from the Jackson Laboratories, Bar Harbor, Maine, or from the Upjohn colony which was started from breeding stock received from Bar Harbor. The T-KK mice were obtained from the Upjohn colony which was established by inbreeding the offspring of the $\mathrm{C} 57 \times \mathrm{KK}$ cross [13]. All animals were housed in groups of $1-12$ animals in wire cages or plastic boxes. They were fed Purina Mouse Breeder Chow and water ad libitum unless otherwise noted. The T-KK used in these studies were all obese, hyperinsulinemic and mildly hyperglycemic at some stages of their lives.

\section{Biochemical Measurements}

Blood was collected from the orbital sinus into a small tube containing a drop of heparin $(100 \mathrm{U} / \mathrm{ml})$. Blood glucose was determined in whole blood by microAutoAnalyzer ${ }^{\circledR}$ [14]. Plasma insulin was determined using the cellulose immunoassay procedure [15]. Growth hormone was determined in plasma using the double antibody radio-immunoassay procedure described by Schalch and Reichlin [16] and Schindler [17] with minor changes.

\section{Growth Hormone Assay}

${ }^{125}$ I-rat growth hormone (RGH) was prepared by labelling purified RGH (NTAMD-Rat-GH-I-1) using a modification $[18,19]$ of Greenwood and Hunter's procedure [20]. Five $\mu \mathrm{g}$ of $\mathrm{RGH}, 1 \mathrm{mCi}{ }^{125} \mathrm{I}$, and $21 \mu \mathrm{g}$ chloramine $\mathrm{T}$ all in $0.05 \mathrm{M}$ phosphate buffer $\mathrm{pH} 7.45$ were mixed and incubated for exactly 2 min. To stop the reaction, $192 \mu \mathrm{g}$ sodium metabisulfite and $100 \mu \mathrm{l}$ normal human plasma were added. The ${ }^{125} \mathrm{I}-\mathrm{RGH}$ was immediately purified on a Sephadex G-50 column, equilibrated with $0.05 \mathrm{M}$ barbital buffer, $\mathrm{pH} 8.6$ and precoated with $10 \mathrm{mg}$ crystalline BSA per g Sephadex. The RGH was eluted with barbital buffer and collected in $0.3 \mathrm{ml}$ fractions in test tubes containing 1 drop $30 \%$ BSA. Specific activity of the ${ }^{125}$ I-GH was about 200 $\mu \mathrm{Ci} / \mu \mathrm{g}$.

All dilutions were made in $0.01 \mathrm{M}$ phosphosaline buffer $(0.01 \mathrm{M}$ phosphate $0.15 \mathrm{M} \mathrm{NaCl}) \mathrm{pH} 7.6$ with $1 \%$ BSA. Just prior to its use in an assay, the ${ }^{125} \mathrm{~T}$ RGH was repurified on Sephadex G-100, using buffer 
as the eluant. Samples and standard (NTAMD-rat-GHRP-1) were contained in a volume of $0.4 \mathrm{ml}$. Monkey anti-rat GH serum (NIAMD-anti-rat GH serum-1) diluted 1:45000 $(0.1 \mathrm{ml})$ was added to each assay tube. Tubes were incubated overnight at $4^{\circ} \mathrm{C}$. ${ }^{125} \mathrm{I}$-RGH containing about $9000-13000$ DPM was added to each tube. After the tubes were incubated at $4^{\circ} \mathrm{C}$ for 3 additional days, $0.025 \mathrm{ml}$ sodium heparin $(1000 \mathrm{U} / \mathrm{ml})$, $0.1 \mathrm{ml}$ monkey serum (diluted $1: 500$ ) and $0.1 \mathrm{ml}$ antimonkey gamma globulin (Antibodies Inc., Davis, California, dituted 1:50) were added to each tube. The tubes were incubated $18-24 \mathrm{hrs}$ at $4^{\circ} \mathrm{C}$, and then centrifuged. The supernatant and precipitate were separated and counted in a gamma counter.

\section{Changes in Body Weight, Food Intake, Blood Glucose and Plasma Insulin with Age}

Food intake, body weight and blood glucose and plasma insulin were measured $2 \mathrm{~h}$ after refeeding following an overnight fast. Determinations were performed at approximately 1 month intervals in $8 \mathrm{C} 57 \mathrm{BL} / 6$ and 6 T-KK mice from $1 \frac{1}{2}$ to 16 months. Animals were housed individually in plastic boxes divided into four compartments and fed Purina Mouse Chow and water ad libitum.

\section{Life Span Study}

The dates of birth and death were recorded for 24 C57Bl/6 and 53 T-KK mice. Survival curves were constructed by the methods of Cutler and Ederer [21].

\section{Glucose Tolerance}

Overnight fasted $\mathrm{C} 57$ and $\mathrm{T}-\mathrm{KK}$ mice aged 11/2, $41 / 2-5$ and 12 months were given $1.5 \mathrm{~g}$ glucose $/ \mathrm{kg}$ body weight orally.

\section{Growth Hormone Responses}

Plasma growth hormone levels were measured in 6 month old mice after fasting overnight and $10 \mathrm{~min}$. after refeeding. Five different animals were used at each sampling time.

\section{Insulin Tolerance}

Overnight fasted mice (ages 2, 5 and 12 months) were injected subcutaneously with $0.5 \mathrm{U}$ insulin $/ \mathrm{kg}$ body weight (Iletin ${ }^{\circledR}$ Regular, U-40, Lilly). Blood glucose was determined before injection of insulin and 20 , 40, 60 and 120 min after insulin. Different animals were used for each bleeding in order to minimize the effects of stress. Four or five animals were bled per time. Blood sugar changes are expressed as \% change from the 0 time value.

\section{In vivo Gluconeogenesis}

Blood samples were taken immediately before and 6,12 and $20 \mathrm{~min}$ after intraperitoneal injection of $1 \mu \mathrm{M}$ pyruvate-2- ${ }^{14} \mathrm{C}(2-2.5 \mu \mathrm{C})$. Blood sugar, ${ }^{14} \mathrm{C}$ in whole blood, and glucose- ${ }^{14} \mathrm{C}$ were determined as described by Chang and Schneider [22]. Gluconeogenesis was expressed as $\%{ }^{14} \mathrm{C}$ in glucose of total whole blood ${ }^{14} \mathrm{C}$. It is recognized that a number of variables, such as altered glucose oxidation or conversion to glycogen, difference in routes of pyruvate utilization and difference in rates of absorption, could alter the end point used. Other workers however have shown that the amount of glucose converted to $\mathrm{CO}_{2}$ [23] or glycogen is not very important over a $1 \mathrm{~h}$ time period [24]. Since it has also been shown that conversion of pyruvate to glucose in vivo is higher in the fasted than in the fed state and is inhibited by insulin [25], it seems reasonable that the $\%$ of blood ${ }^{14} \mathrm{C}$ in glucose is an acceptable end point to use for estimation of differences in gluconeogenesis [26].

Two experimental designs were used for studies of $i n$ vivo gluconeogenesis. In one study the same animals were tested in both the fed ( 5 months of age) and fasting states (7 months of age). The second experimental approach consisted in studying the animals after refeeding period of $2 \mathrm{~h}$ following an overnight fast (2 months and 13 months old mice).

\section{Glucose Oxidation by Isolated Islets}

Islets were isolated by a modification of the method of Lacy and Kostianorsky [27]. The islets were isolated from the digestion medium with micropipettes (250$400 \mu l)$ and transferred to glass cups fitted to rubber serum stoppers which were placed in scintillation vials for incubation. Incubation was with KRB buffer containing either 100 or $300 \mathrm{mg} \%$ of glucose-I- ${ }^{14} \mathrm{C}$ or $-6-{ }^{14} \mathrm{C}$ with specific activity of $1 \mu \mathrm{Ci} / \mathrm{mg}$. Medium was gassed for 5 min with $95 \% \mathrm{O}_{2}$ and $5 \% \mathrm{CO}_{2}$. Incubation was at $37^{\circ} \mathrm{C}$ for $1 \mathrm{~h}$. At the end of $1 \mathrm{~h}, 0.1 \mathrm{ml}$ Hyamine was added to the bottom of the scintillation vial and $0.1 \mathrm{ml}$ of $1 \mathrm{~N} \mathrm{HCl}$ to each incubation cup. Incubation was continued $1 \mathrm{~h}$. after which Bray's scintillation fluid was added to the vials. Counting was done in a Packard Tri-Carb. After incubation, the islets were rinsed with water, transferred to a pre-weighed aluminum boat and dried to a constant weight.

\section{Results}

Food intake $(\mathrm{g} / 24 \mathrm{~h})$ of T-KK mice was increased at 2 months of age and remained elevated for 8 months. At 9-16 months, food consumptions of T-KK and C57 mice were very similar (Fig. 1). Body weights of T-KK mice were greater than those of $\mathrm{C} 57$ mice at 2-8 months of age. After 9 months, body weights of the T-KK began to decrease; at 12-16 months, they were less than those of C57's (Fig. 2). Blood glucose of $2 \mathrm{~h}$ refed T-KK mice was elevated from 2 to 6 months, normal between 8 and 10 months and below normal at 8-16 months (Fig. 3). Plasma insulin of fed T-KK mice was elevated by 2 months, increased from $200 \mu \mathrm{U} /$ $\mathrm{ml}$ to $4500 \mu \mathrm{U} / \mathrm{ml}$ by 5 months of age. Between 5 and 9 months, plasma insulin gradually decreased in the 
T-KK mice; from 9 months on, it decreased rapidly to almost normal levels (Fig. 4).

Decreased tolerance to an oral glucose load was already manifest in T-KK mice by age 2 months and remained abnormal to at least age 5 months. By 12 months, the glucose tolerance of the T-KK mice had improved over that of the younger ages; at this age, the T-KK mice were more tolerant to glucose loading

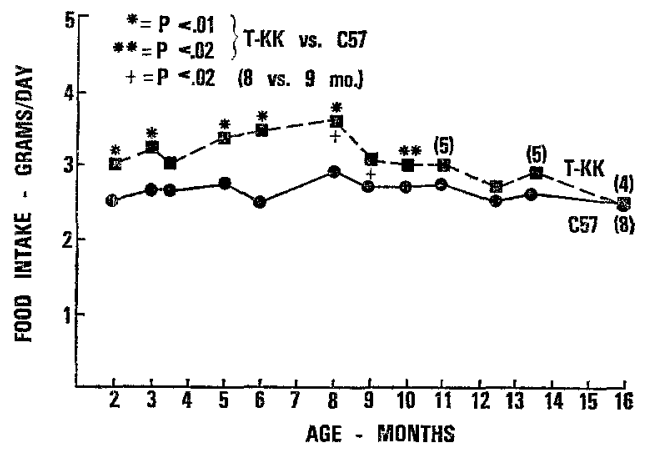

Fig. 1. Food intake $(\mathrm{g} / 24 \mathrm{~h}$ ) with age of T-KK and C57 mice. 6 T-KK for each point except at $12 \frac{1}{2}, 13 \frac{1}{2}$ and 16 months (numbers indicated on graph). $8 \mathrm{C} 57$ at each time period

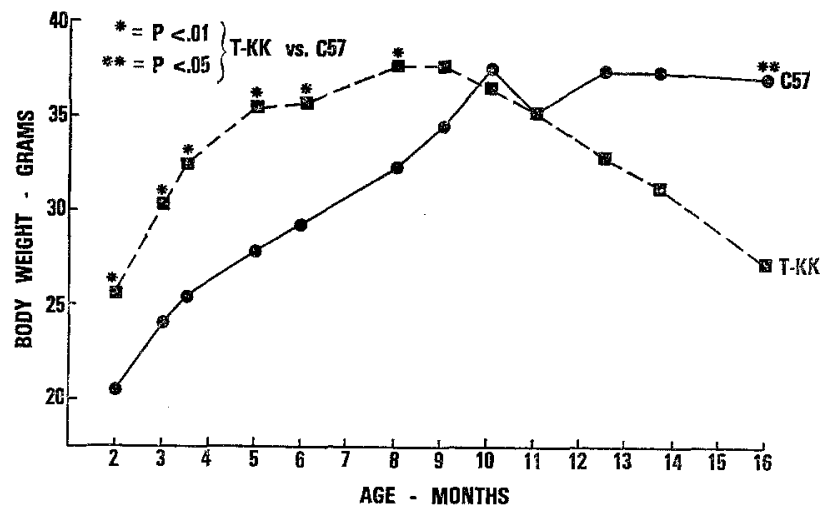

Fig. 2. Body weight changes with age of T-KK and C57 mice. 6 T-KK mice for each point except at $121 / 2,131 /$ and 16 months at which time there were 5,5 and $4.8 \mathrm{C} 57$ mice

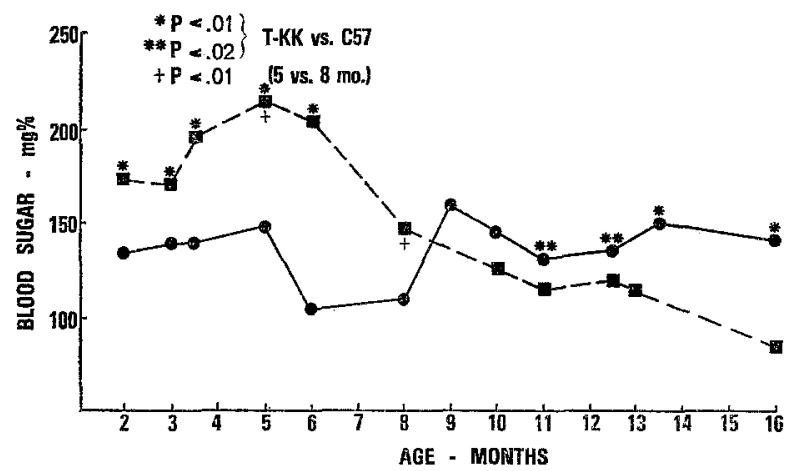

Fig. 3. Blood sugar changes with age of T-KK and C57 mice than C57 mice of the same age (Fig. 5, 6). Fasted T-KK mice were slightly insensitive to the blood sugarlowering action of exogenous insulin at 2 months, markedly insensitive at 5 months and more sensitive at 12 months than $\mathrm{C} 57 \mathrm{BL} / 6$ mice of comparable ages (Fig. 7, 8).

The ability of fed T-KK mice of 2 and 5 months of age to convert intraperitoneally administered pyruvate- ${ }^{14} \mathrm{C}$ to glucose- ${ }^{14} \mathrm{C}$ expressed as ${ }^{\circ}{ }^{14} \mathrm{C}$ in blood as glucose of total whole blood ${ }^{14} \mathrm{C}$ (gluconeogenesis) was elevated as compared with C57 mice of the same age (Fig. 9, 10). Fed. T-KK mice at age 12 months showed

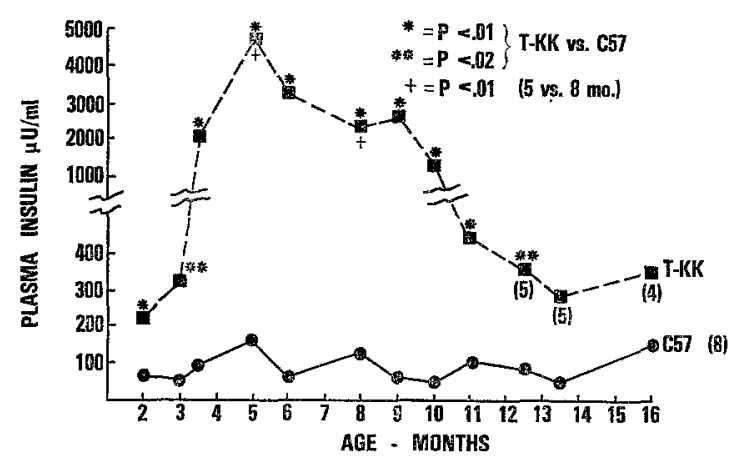

Fig. 4. Changes in plasma insulin with age of T-KK and C57 mice. 8 T-KK for each point except at $12 \frac{1}{2}, 13 \frac{1}{2}$ and 16 months when there were 5,5 and 4.8 C57 mice at each ag'o

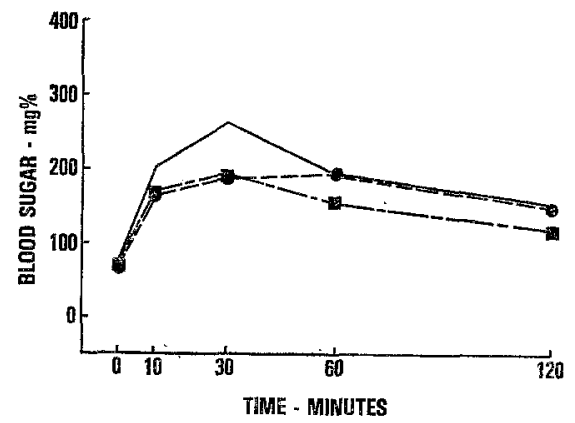

Fig. 5. Oral glucose tolerance after $1.5 \mathrm{~g}$ of glucose $/ \mathrm{kg}$ of C57 mice. $-=2$ months old; $-1 .-1 / 2$ to 5 months old; $\mathbf{D}-\mathbf{D}=12$ months old; $\mathrm{N}=5$

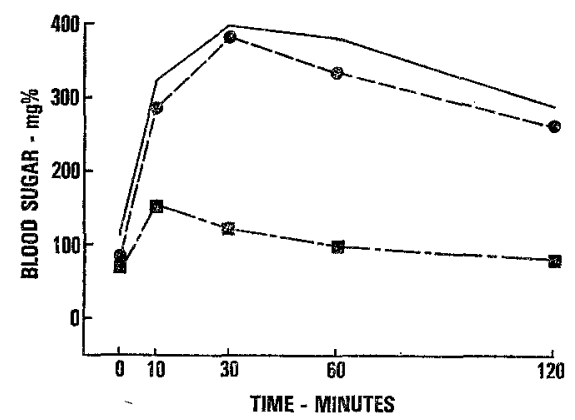

Fig. 6. Oral glucose tolerance after $1.5 \mathrm{~g}$ glucose $/ \mathrm{kg}$ of T-KK mice. $-=11 / 2$ months old $(\mathrm{N}=4) ; 0-\ldots=41 / 2$ to 5 months old $(\mathrm{N}=5)$; $-\longrightarrow-12$ months old $(\mathrm{N}=4)$ 
decreased gluconeogenesis compared with C57's of the same age (Fig. 11). Fasted T-KK and C57 mice at age 7 months exhibited the same rate of gluconeogenesis (Fig. 12). There was no difference between the rate of gluconeogenesis of 5 month old fed and 7 month old fasted T-KK mice (Fig. 10, 12). In contrast the fed C57's at age 5 months converted considerably less pyruvate into glucose than the fasted C57's at age 7 months (Fig. 10, 12).

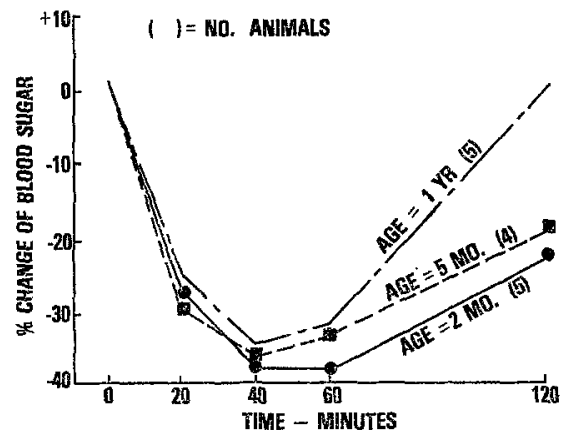

Fig. 7. Insulin sensitivity of $\mathrm{C57}$ mice at different ages; 4-5 animals/point. Overnight fasted mice were injected subcutaneously with $0.5 \mathrm{U}$ insulin/kg body weight

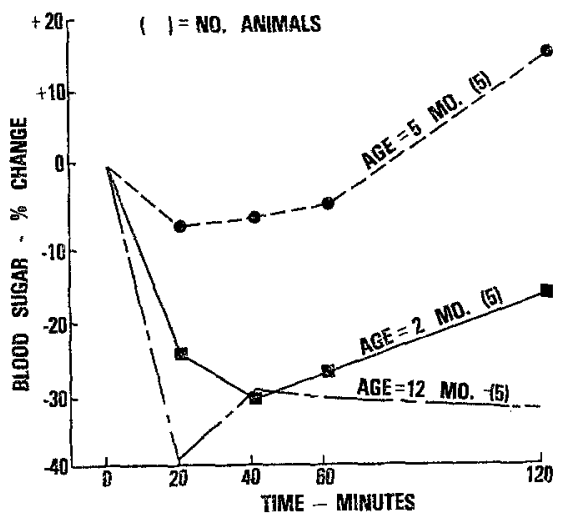

Fig. 8. Insulin sensitivity of T-KK mice at different ages 4-5 animals/point. Overnight fasted mice were injected subcutaneously with $0.5 \mathrm{U}$ insulin/kg body weight

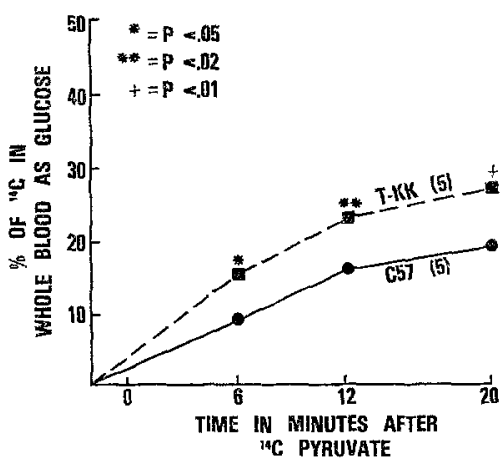

Fig. 9. Per cent of ${ }^{14} \mathrm{C}$ in whole blood as glucose $-{ }^{14} \mathrm{C}$ in $2 \mathrm{~h}$ refed 2 month old T-KK and C57 mice after intraperitoneally administered pyruvate $-14 \mathrm{C}$. $(\mathrm{l})=$ No. animals
The life span of the T-KK mice was approximately 10 months less than that of the C57 mice (Fig. 13). It should be noted that the early deaths of the T-KK's coincided with the normalization of food intake, plasma insulin, body weight and blood sugar. Plasma growth hormone levels in 6 month old fasted. T-KK mice were significantly lower than those in C57 controls (Fig. 14). The increase, however, in plasma growth hormone $10 \mathrm{~min}$ after refeeding was the same in both species (Fig. 14). Oxidation of glucose $1 .{ }^{14} \mathrm{C}$ and $\cdot 6-{ }^{14} \mathrm{C}$

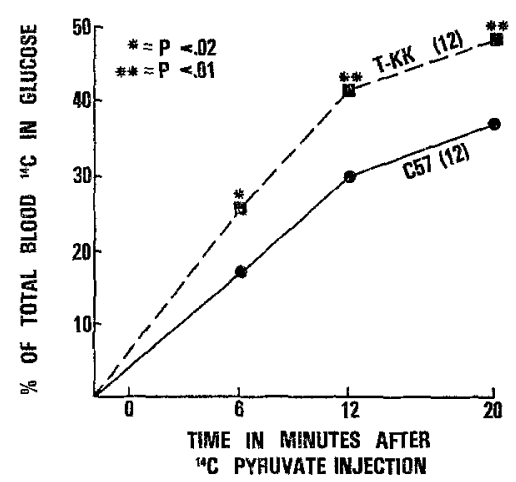

Fig. 10. Per cent of ${ }^{14} \mathrm{C}$ in whole blood as glucose- ${ }^{14} \mathrm{C}$ in fed 5 month old T-KK and C57 mice following intraperitoneally administered pyruvate- ${ }^{14} \mathrm{C} .()=$ No. animals

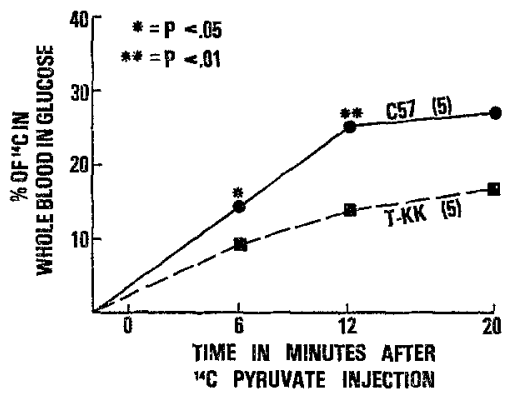

Fig. 11. Per cent of ${ }^{14} \mathrm{C}$ in whole blood as glucose ${ }^{14} \mathrm{C}$ in 1 year or old refed T-KK and C57 mice after intraperitoneally administered pyruvate- ${ }^{14} \mathrm{C} .()=$ No. animals

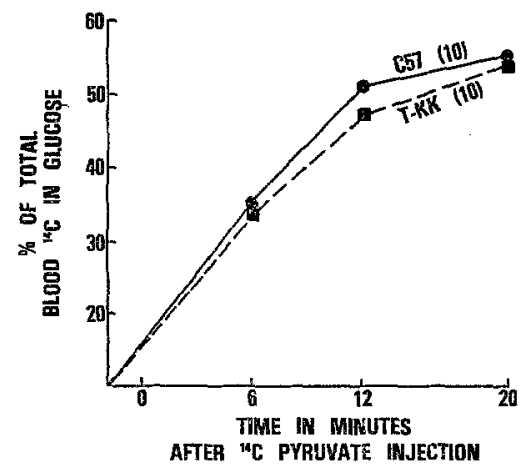

Fig. 12. Per cent of ${ }^{14} \mathrm{C}$ in whole blood as glucose ${ }^{14} \mathrm{C}$ in fasted 7 months old T-KK and C57 mice after intraperitoneally administered pyruvate-14 $\mathrm{C} .()=$ No. animals 
at glucose concentrations of 100 and $300 \mathrm{mg} \%$ was higher in islets isolated from T-KK mice compared to those of $\mathrm{C} 57$ mice (Fig. 15).

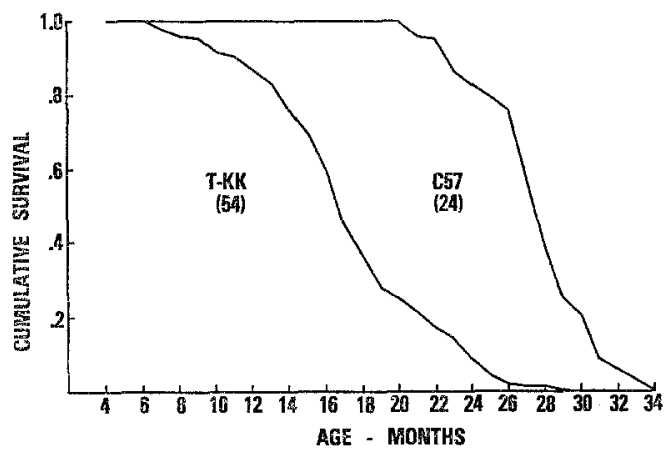

Fig. 13. Survival curves for T-KK and C57 male mice. ()$=$ No. animals

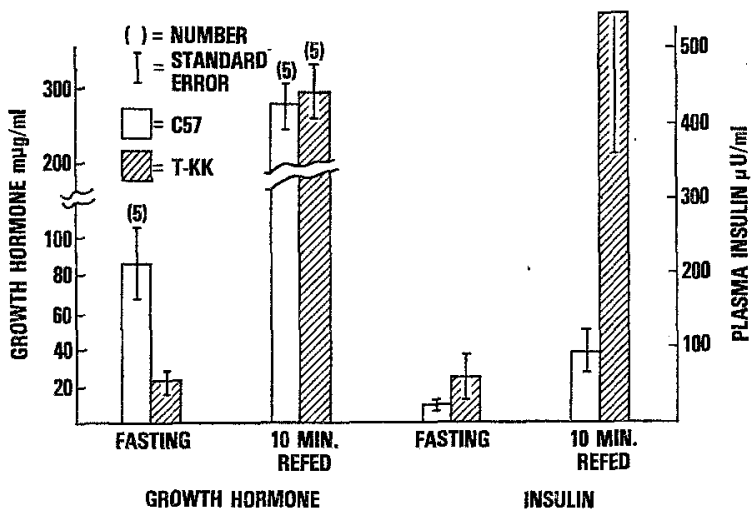

Fig. 14. Plasma growth hormone in 6 month old T-KK and 057 mice in the fasting state or 10 min after refeeding

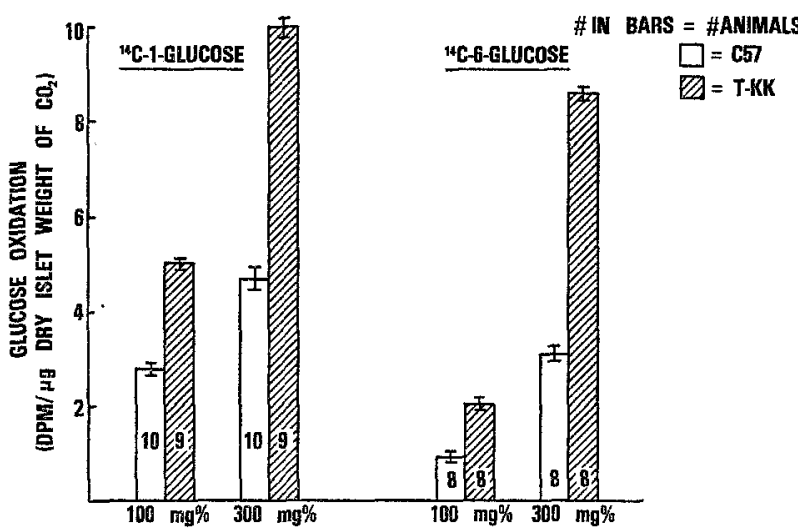

Fig. 15. Oxidation of glucose $-1{ }^{14} \mathrm{C}$ and glucose-6-1 ${ }^{14} \mathrm{C}$ by isolated islets from T-KK and C57 mice (age 7-12 months)

\section{Discussion}

One of the most interesting observations reported on the T-KK, KK and other diabetic mice was that the characteristic manifestations of this syndrome such as obesity, hyperphagia, hyperinsulinemia and glucose intolerance have been reported to revert to normal as the animals approached 1 year of age $[3,13,28]$. The understanding of the physiological mechanisms responsible for the development and regression of these abnormalities will provide us with guidelines as to how selectively to alter specific environmental parameters to prevent or normalize the diabetic state. The principal objectives of the studies described in this paper were to study as many parameters as possible during the life span of the animals in an effort to determine the primary changes involved in the development and regression of the diabetic state in the T-KK mouse.

It was not possible to determine the first change which occurs in the T-KK mouse since hyperglycemia, hyperinsulinemia, glucose intolerance, insensitivity to insulin and excessive gluconeogenesis were all evident at 2 months of age, which was the earliest age studied. Evaluation of these parameters at an earlier age will be required. However, since less than $50 \%$ of the T-KK mice exhibit the abnormalities described in this paper, studies at an earlier age are impractical $[6,13]$.

It was unexpected to find that blood sugar and plasma insulin normalization preceded the decrease in food intake or body weights, since it has been observed that excessive food intake and obesity increase blood sugar and plasma insulin levels $[5,8,29,30,31]$ and that food limitation will often restore the blood sugar and insulin levels to normalcy $[5,13,30]$. It therefore seems reasonable to conclude that normalization of plasma insulin and blood sugar are under genetic control.

A normal metabolic state is generally considered to be desirable. This, however, was not the case in the T-KK mice since the age when their abnormalities began to normalize coincided with the age at which they began to die.

The hyperglycemia of the T-KK mice was maximal at 4-6 months of age. The reason for the hyperglycemia in spite of the highly elevated circulating insulin can be explained by previous observations of insensitivity of muscle and fat tissues to insulin in vitro [5], decreased sensitivity to injected insulin in vivo, and increased gluconeogenesis. It is important to note, however, that the increased gluconeogenesis occurred only in the fed state. This is consistent with the observations that the fasting blood sugars of T-KK are often normal $[5,13]$ and that they only exhibit hyperglycemia in the fed state. These observations suggest that the gluconeogenic enzymes are not inhibited by the high level of plasma insulin which occurs in the fed animals. These data are consistent with those reported by Appel et al. [10] showing that the gluconeogenic enzymes are elevated in livers of fed T-KK mice.

In an attempt to understand the reason for the abnormal changes in the T-KK mouse, plasma growth hormone and islet glucose oxidation were measured. Growth hormone has been implicated in the development of diabetes in humans $[32,33,34]$ and in the KK 
mouse [4] and can induce diabetes in the dog [35]. Data presented in this paper show that suppressed rather than elevated levels of growth hormone were present in the fasted T-KK mouse. It can therefore be concluded that elevated growth hormone does not contribute to the abnormalities seen in the T-KK mouse. It was of interest to find that the islets were hyperactive in the T-KK mouse as demonstrated by increased glucose oxidation. The increased glucose oxidation correlated with the increased ability of the islets to release insulin and to synthesize insulin in vitro [10]. It is not known whether the hyperactivity of the islets is environmentally induced or whether it is inherent in the islets.

The causes of development and regression of the abnormalities in the T-KK mouse are still not clearly understood, even though considerable data are available. The cause of reversal toward normalcy of some of the symptoms in this diabetic mouse may be under genetic control since factors such as decrease in food intake and body weight, which would be expected to influence this reversal, occur after the other parameters have begun to normalize.

\section{References}

1. Kondo, K.K., Nozawa, T., Tomida, T., Ezaki, K.: Inbred strains resulting from Japanese mice. Bull. exp. Animals 6, 107-112 (1957)

2. Nakamura, M.: A diabetic strain of the mouse. Proc. Jap. Acad. 38, 348-352 (1962)

3. Nakamura, M., Yamada, K.: Studies on a diabetic (KK) strain of mouse. Diabetologia 3, 212-221 (1967)

4. Nakamura, M.: Estimation of the adenohypophysial growth hormone control in the diabetic " $\mathrm{KK}$ " mouse strain by acrylamide gel electrophoresis. Proc. Jap. Acad. 42, 512-516 (1966)

5. Dulin, W.E., Wyse, B.M. : Insulin secretion in early diabetic animals, in vivo studies. In: Early Diabetes. Camerini-Davalos, R., Cole, H.S. (eds.) pp. 71-77. New York and London: Academic Press 1970

6. Butler, L.: The inheritance of glucosuria in the KK and $A^{y}$ mouse. Canad. J. Genet. Cytol. 14, 265-269 (1972)

7. Iwatsuka, H., Shino, A., Suzuaki, Z.: General survey of diabetic features of yellow KK mice. Endocr. jap. $17,23-25(1970)$

8. Matsuo, T., Shino, A., Iwatsuka, H., Suzuoki, Z.: Induction of overt diabetes in KK mice by dietary means. Endocr. jap. 17, $477-488$ (1970)

9. Matsuo, T., Furumo, K., Shimakawa, K.: Factors affecting development of hyperglycemia in $\mathrm{KK}$ mice. J. Takeda Res. Lab, 30, 307-313 (1971)

10. Appel, M.C., Chang, A.Y., Dulin, W.E.: Diabetes in the Toronto-KK hybrid mouse. Abnormalities in liver and pancreatic islets of Langerhans. Diabetologia 10, $625-632(1974)$

11. Iwatsuka, H., Shino, A.: Studies on diabetic action of obesity in mice: congenital insulin resistance of $\mathrm{KK}$ mice. Endocr. jap. 17, 535-540 (1970)
12. Iwatsuka, H., Matsuo, T., Shino, A., Suzuoki, Z.: Metabolic disturbance of KK mice in chemical diabetes. J. Takeda Res. Lab. 29, 685-692 (1970)

13. Dulin, W.E., Wyse, B.M.: Diabetes in the KK mouse. Diabetologia 6, 317-323 (1970)

14. Gerritsen, G.C., Dulin, W.E.: Effect of a new hypoglycemic agent, 3,5-dirnethylpyrazole on carbohydrate and free fatty acid metabolism. Diabetes 14, 507-515 (1965)

15. Zaharto, D.S., Beck, L.V.: Studies of a simplified plasma insulin immunoassay using cellulose powder. Diabetes 17, 444-457 (1968)

16. Schalch, D.S., Reichlin, S.: Plasma growth horrnone concentration in rat determined by radioimmunoassay. Endocrinology 79, 274-280 (1966)

17. Schindler, W.J., Hutchins, M.O., Sepimus, E.J.: Growth hormone secretion and control in the mouse. Endocrinology 91, $483-490$ (1972)

18. Niswender, G.D., Reichert, L.E., Jr., Midgley, A.R., Nalbandov, A. V.: Radioimmunoassay for bovine and ovine Iuteinizing hormone. Endocrinology 84, 11661173 (1969)

19. Schalch, D.A.: Use of $\mathrm{J}^{125}$ labelling in radioimmunoassay. Proc. Soc. exp. Biol. (N.Y.) 121, 1279 $\rightarrow 1280$ (1966)

20. Greenwood, F.C., Hunter, W.M.: The preparation of $I^{131}$-labelled human growth hormone of high specific radioactivity. Biochem. J. 89, 114-123 (1963)

21. Cutler, S.J., Ederer, F.: Maximum utilization of the life table method in analyzing survival. J. chron. Dis. $8,699-712(1958)$

22. Chang, A.Y., Schneider, D.I.: Metabolic abnormalities in the pancreatic islets and livers of the diabetic Chinese hamster. Diabetologia 6, 180-185 (1970)

23. Miller, W.L., Krake, J.J., Vander Brook, M.J.: Studies on the utilization of uniformily labeled $\mathrm{C}^{\mathbf{1 4}}$ glucose by rats given tolbutamide (Orinase). J. Pharmacol. exp. Therap. 119, 513-521 (1957)

24. Ashmore, J., Cahill, G.F., Earle, S.A.: Studies on the disposition of isotopic glucose in vivo and in vitro under the influence of sulfonylureas. Ann. N. Y. Acad. Sci. 71, $131-140$ (1957)

25. Friedman, B., Goodman, E.H., Weinhouse, S.: Effects of insulin and fatty acids in gluconeogenesis in the rat. J. biol. Chem. 242, 3620-3627 (1967)

26. Friedemann, B., Goodman, E.H., Weinhause, S.: Dietary and hormonal effect on gluconeogenesis and gilycog'enesis from pyruvate-3- ${ }^{14} \mathrm{C}$, fructose-U-14 $\mathrm{C}$ and glycerol-2 ${ }^{14} \mathrm{C}$ in the rat. Endocrinology 86, 1267$1271(1970)$

27. Lacy, P.E., Kostianovsky, M.: Methods for the isolation of intact islets of Langerhans from the rat pancreas. Diabetes 16, 35-39 (1967)

28. Herberg, L., Major, E., Hennig's, U., Grüneklee, G., Freytag, G., Gries, F.A.: Differences in the development of the obese-hyperglycemic syndrome in obob and NZO mice. Diabetologia 6, $292-299$ (1970)

29. Bray, G.A., York, D.A.: Genetically transmitted obesity in rodents. Physiol. Rev. 51, 598-646 (1971)

30. Cahill, G.F., Jones, E. E., Lauris, V., Steinke, J., Soeldner, J.S.: Studies on experimental diabetes in the Wellesley hybrid mouse. Diabetologia 3, 171-174 (1967) 
31. Frohman, L.A., Goldman, J.K., Bernardia, L.L.: Studies of insulin sensitivity in vivo in weanling rats with hypothalmic obesity. Metabolism. 21, 1133-1142 (1972)

32. Barrd, J.D., Hunter, W.M.: The relationship between human growth hormone and the development of diabetes mellitus and its complications. Postgrad. med. J. 49, (Suppl. 1) 132-140 (1973)

33. Assan, R., Tchobroutsky, G.: Serial plasma growth hormone levels in 33 cases of severe diabetic ketoacidosis. Effects of sodium nicotinate. Horm. Metab. Rev. 4, 317-321 (1972)

34. Johansen, K., Hansen, A.P.: High $24 \mathrm{~h}$ level of serum growth hormone in juvenile diabetics. Brit. med. J. 1969 II, $556-557$

35. Campbell, J.: Diabetogenic actions of growth hormone. In: Hypophyseal Growth Hormone, Nature and Actions. Smith, R.W., Gaebler, O.H., Long, C.N.H. (eds.) pp. 270-285. New York: MeGraw Hill Book Co., Inc., The Blackiston Division 1955

B.M. Wyse

Diabetes and Atherosclerosis Research

The Upjohn Company

Kalamazoo, Mich. 49001

USA 